\title{
Changes in summer monsoon rainfall in the Upper Chao Phraya River Basin, Thailand
}

\author{
Nkrintra Singhrattna*, Mukand Singh Babel
}

Water Engineering and Management (WEM), Asian Institute of Technology (AIT) Klong Luang, Pathumthani, Thailand

\begin{abstract}
We determined the effects of climate change on pre-monsoon (May-June-July: MJJ) and monsoon (August-September-October: ASO) season rainfall in the Upper Chao Phraya River Basin, Thailand, by downscaling surface rainfall from large-scale atmospheric variables, i.e. surface air temperature (SAT), sea level pressure (SLP), and zonal and meridional wind ( $u$ and $v$, respectively). The data were obtained from the Geophysical Fluid Dynamics Laboratory (GFDL) model and used as predictors in a modified $k$-nearest neighbor ( $k$-nn) model. Under climate change scenarios A2 and B2, during 2011-2100, the increasing trends of annual SAT over northern Thailand and the South China Sea vary from 1.65 to $3.47^{\circ} \mathrm{C}$ century ${ }^{-1}$. By the end of the 21st century, the annual SAT anomalies range from +2 to $+10^{\circ} \mathrm{C}$. The increasing trends of annual SLP over the Gulf of Thailand and northern Thailand range from 0.40 to $0.83 \mathrm{mb}$ century ${ }^{-1}$. Depending upon the regions and scenarios, increasing and decreasing trends of annual $u$ and $v$ were observed. From the modified k-nn model, the effects of climate change on MJJ and ASO rainfall indicate decreasing trends during 2011-2100 with a maximum decrease by $6.16 \mathrm{~mm} \mathrm{yr}^{-1}$, corresponding to the ASO rainfall under Scenario B2. In terms of effects on the frequency of extreme events, dry (wet) conditions during 2011-2100 showed a greater (lesser) chance of occurrence than the climatology, with the exception of ASO rainfall under the Scenario A2, which showed a greater chance of being both dry and wet. With a probability $>70 \%$, dry MJJ and ASO conditions will be observed more often than wet, especially the dry ASO under Scenario B2, which was predicted for the $55 \mathrm{yr}$ from $2046-2100$.
\end{abstract}

KEY WORDS: Climate change $\cdot$ Thailand rainfall $\cdot$ Upper Chao Phraya River Basin $\cdot$ Ping River Basin

Resale or republication not permitted without written consent of the publisher

\section{INTRODUCTION}

Thailand, located in Southeast Asia between 5 and $20^{\circ} \mathrm{N}$ latitude and 97 to $106^{\circ} \mathrm{E}$ longitude, connects with 2 large oceans: the Indian Ocean and the Pacific Ocean. The climate of Thailand is influenced by both oceans via atmospheric-oceanic circulation. The average annual temperature ranges from 26.3 to $28.0^{\circ} \mathrm{C}$, with the maximum temperature in April varying from 31.6 to $33.6^{\circ} \mathrm{C}$. The average annual rainfall is 1200 to $1600 \mathrm{~mm}$ (TMD 2010). The summer monsoon season caused by the southwest monsoon and the Inter Tropical Convergence Zone (ITCZ) lasts from mid-May to mid-October. The pre-mon- soon season is influenced by the southwest monsoon and the ITCZ moving from the Indian Ocean to Thailand in May and to central China in mid-June. Subsequently, the monsoon season is associated with the ITCZ moving back to cover Thailand during August to October.

The major occupation in Thailand is agriculture, which is a rain-fed system. Therefore, severe socioeconomic problems are caused by rainfall variability and extreme weather events, e.g. flooding and drought. Several potential factors, including land use change (Croke et al. 2004, Bronstert 2004), deforestation (Kanae et al. 2001), and atmospheric variability, are responsible for the hydrological fluctuations in 
terms of intensity and frequency of extreme events. Increasing greenhouse gas concentrations, in particular $\mathrm{CO}_{2}$, greatly influence global warming (Mitchell 1989, Maslin 2007, NIC 2009, NASA 2010). Consequently, climate change is expected to occur due to increasing global surface temperatures (UNEP 2003, Trenberth 2008). Since rainfall in Thailand shows significant links to large-scale atmospheric variables (LSAVs), e.g. temperature and pressure (Chen \& Yoon 2000, Singhrattna et al. 2005b), the changing climate affects rainfall via atmospheric-oceanic circulations. The objective of this study was to determine the effects of climate change on summer monsoon season rainfall in the Upper Chao Phraya River Basin (Thailand). Rainfall simulation by a stochastic statistical model is a tool for long-term planning in water resources and an adaptation strategy to deal with future climate change.

\section{METHODS}

Based on the significant relationships between local hydroclimates (e.g. precipitation) and LSAVs (e.g. sea level pressure), LSAVs have been used as predictors in multiple regressions to forecast hydroclimates (Hamlet et al. 2002, McCabe \& Dettinger 2002, Singhrattna et al. 2005a, Koocheki et al. 2006, Moriondo \& Bindi 2006). Moreover, with an assumption that general circulation models (GCMs) simulate atmospheric variables in the upper air level, e.g. temperature and pressure, more reliably than surface variables, e.g. precipitation, regressions incorporating LSAVs are also applied to downscale regional and local surface hydroclimates from variables in the upper air level. The GCM outcomes are the forecasted future climate, which is expected to change relative to future environmental systems and human activities. GCMs provide projected data of LSAVs under several climate change scenarios proposed by the Intergovernmental Panel on Climate Change (IPCC). The proposed scenarios incorporate differences in socioeconomic, demographic, and technological growth and environmental changes such as greenhouse gas concentrations, in particular $\mathrm{CO}_{2}$. The model resolution in terms of spatial gridded coverage varies from $2.8^{\circ}$ longitude $\times 2.8^{\circ}$ latitude to $5.6^{\circ}$ longitude $\times 5.6^{\circ}$ latitude. The length of data series ranges series from 100 to $211 \mathrm{yr}$ (see also IPCC 2001).

In terms of regression analysis, although parametric approaches, e.g. linear regression, have been widely applied due to their simplicity, there are some drawbacks of fitting a regression by parametric approaches, such as a prior assumption of relationships between dependent and independent variables and a method of global fitting. Therefore, nonparametric approaches were developed and adopted to improve the fitting performance. Without a prior assumption, the fitting functions of nonparametric approaches can locally capture the relationships between dependent and independent variables or fit the regression at a given point by a small set of neighbors. Hence, the nonparametric approaches are flexible and able to fit any arbitrary, e.g. bivariate and multivariate data. There are several approaches of nonparametric regression. One that was developed to capture the discontinuities of the derivative curve is the spline approach. Another approach that applies a regression locally to a given point and its neighbors is called 'local polynomials.' This approach includes locally weighted polynomials (Loader $1999)$ and $k$-nearest neighbor ( $k$-nn) local polynomials (Owosina 1992, Rajagopalan \& Lall 1999). In this study, aiming to determine the effects of climate change and downscale rainfall from LSAVs of a GCM, the modified $k$-nn model was adopted to fit the regression between summer monsoon season rainfall and identified atmospheric predictors.

\subsection{Study area}

There are 25 major river basins in Thailand. The largest basin is the Chao Phraya River Basin, which is located in central Thailand and covers an area of $178000 \mathrm{~km}^{2}$, i.e. $35 \%$ of the country's land area. The Upper Chao Phraya River consists of 4 tributaries: Ping, Wang, Yom, and Nan Rivers. Our study area, i.e. the Ping River Basin, covers a drainage area of $33899 \mathrm{~km}^{2}$ with a river length of $740 \mathrm{~km}$ originating in northern Thailand (Fig. 1). The irrigated area of the study basin covers $2332 \mathrm{~km}^{2}$. Although the basin receives a sufficient runoff of 8700 million $\mathrm{m}^{3}$ (MCM) $\mathrm{yr}^{-1}$ for an average annual demand of $6127 \mathrm{MCM}$, water shortage especially in the upstream region is evident during the dry season. An average annual inflow of 5900 MCM from the Ping River Basin is stored in a reservoir of the Bhumipol Dam located downstream of the Ping River. The Bhumipol Dam was constructed for the purposes of hydropower production, agricultures, fishery, transportation, and flood mitigation. The maximum storage capacity is $13462 \mathrm{MCM}$ with a hydropower capacity of $780 \mathrm{MW}$. The dam regulates and supplies water to the downstream area, e.g. the Lower Chao Phraya River Basin, which has an irrigated area of $6878 \mathrm{~km}^{2}$. The domes- 


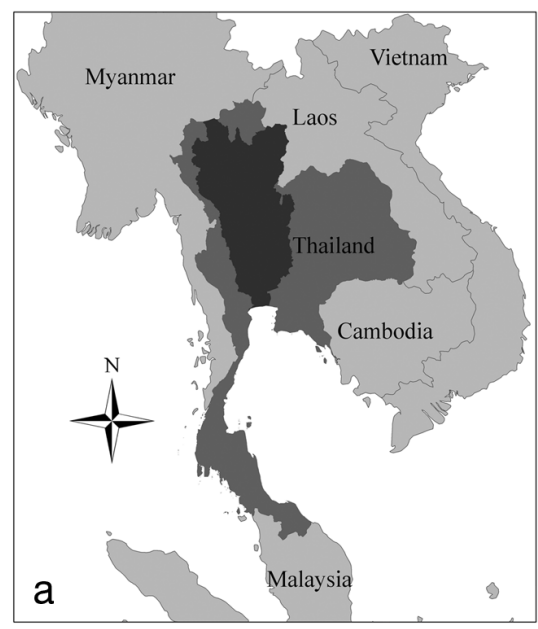

Fig. 1. (a) Thailand and (b) Upper Chao Phraya River Basin: Ping, Wang, Yom, and Nan River Basins

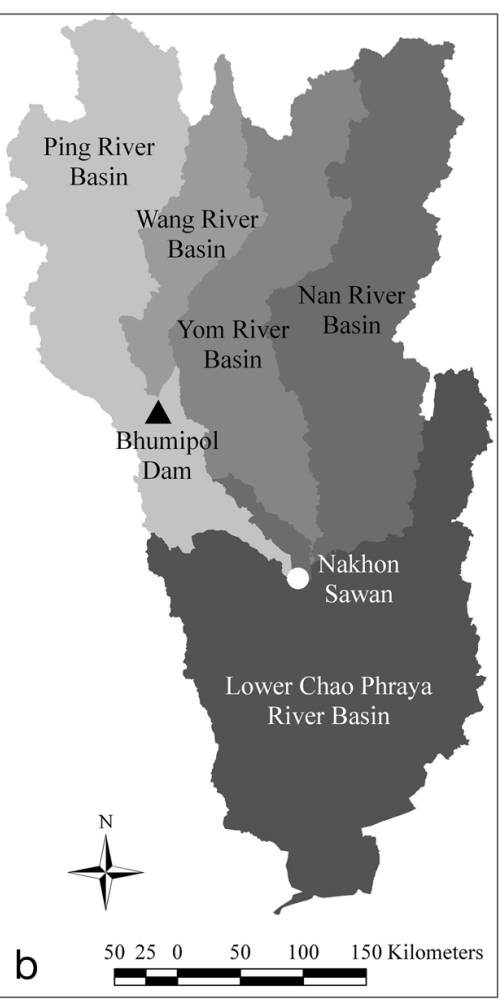

selected stations was significantly correlated at the $95 \%$ confidence level by Fisher's transformation (Haan 2002), with the correlation coefficients ranging from 0.46 to 0.96 , the monthly rainfall was averaged over the 50 selected stations. The annual cycle of rainfall (Fig. 3) has 2 peaks influenced by the southwest monsoon and the ITCZ. The secondary peak is found during May-June-July (MJJ), i.e. the pre-monsoon season, during which the southwest monsoon and the ITCZ bring moisture from the Indian Ocean to Thailand, and subsequently to the South China Sea and central China. The primary peak during August-September-October (ASO) corresponding to the monsoon season rainfall is caused by the ITCZ moving back to Thailand. As a result, the pre-monsoon and monsoon season rainfall are the sums of rainfall during MJJ and ASO, respectively. tic and total water demand in the Chao Phraya River Basin is estimated to be 2240 and $11000 \mathrm{MCM} \mathrm{yr}^{-1}$, respectively. The water management and planning of the Ping River Basin influence the socioeconomics of this basin and downstream areas. Hence, the Ping River Basin was selected to investigate the effects of climate change on rainfall, with the aim of developing a sustainable plan for water resource use.

\subsection{Data}

\subsubsection{Observed data}

Data on daily rainfall from 1950-2007 were obtained from 50 selected stations located in and around the Ping River Basin (Fig. 2). All stations were selected based on the length of time series and whether incomplete data represented less than $5 \%$ of the 30 recent years of data. The data of all 50 stations were provided by the Royal Irrigation Department of Thailand, the Thailand Meteorological Department, and the Department of Water Resources. Because the monthly rainfall from 1950-2007 of all 50

Fig. 2. Rainfall stations in and around the Ping River Basin, Thailand

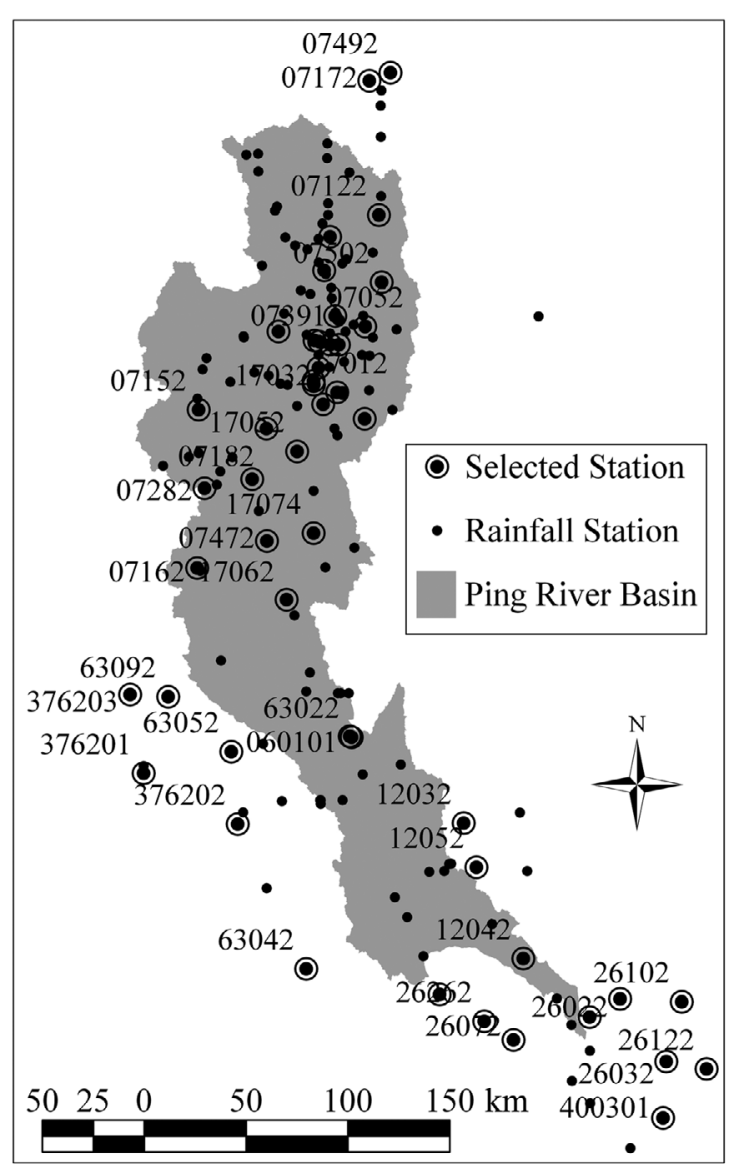




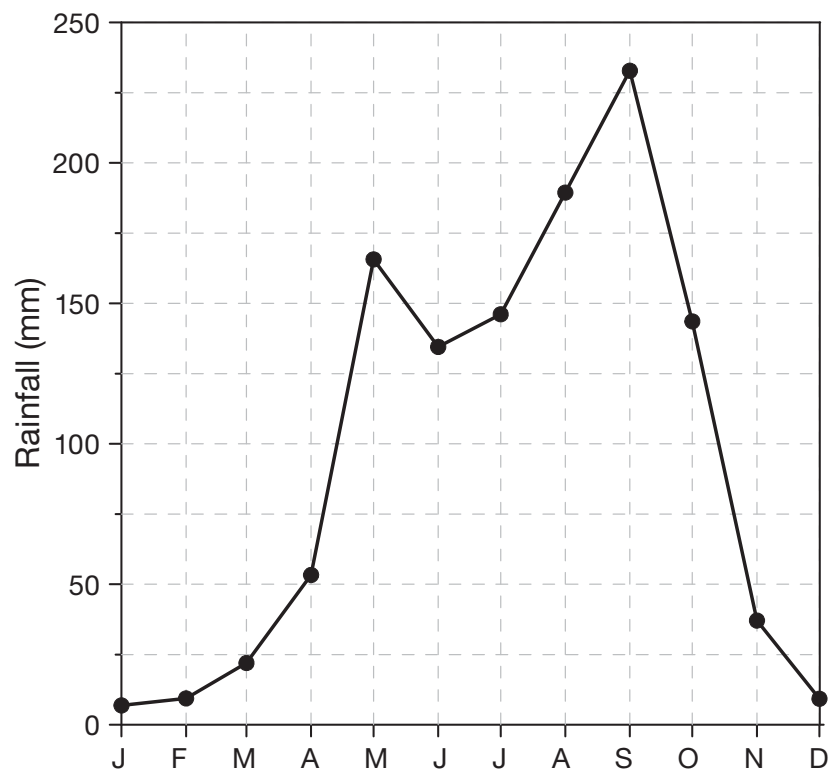

Fig. 3. Annual cycle of mean monthly rainfall averaged over 50 selected stations during 1950-2007

In terms of LSAVs, 4 principal variables, i.e. surface air temperature (SAT), sea level pressure (SLP), surface zonal wind $(u)$, and surface meridional wind $(v)$ were used as the independent variables or predictors of the pre-monsoon (MJJ) and monsoon (ASO) season rainfall in a multivariate regression (Singhrattna et al. in press). Based on significant correlations at the 95\% confidence level between rainfall (during MJJ and ASO) and 4 LSAVs, the spatial coverage (Table 1) of 4 predictors was identified by crosscorrelation maps (Grantz et al. 2005, Schöngart \& Junk 2007). The correlation maps are the interactive plots and analysis provided by the Earth System Research Laboratory (ESRL) of the National Oceanic Atmospheric Administration (NOAA; ESRL 2008). The nonlinear temporal relationships between rainfall and LSAVs are observed from the correlation maps. Few significant correlations were found during 1950-2007; however, the relationships developed after 1980 were significant at the 95\% confidence level. The nonlinear interdecadal relationships are influenced by the subsidence of the Walker circulation on Thailand and Southeast Asia after 1980, which are associated with the shifting regions of sea surface temperature anomalies in the Pacific Ocean (Krishna Kumar et al. 1995, Singhrattna et al. 2005b). Corresponding to the identified regions of predictors by the correlation maps, the observed LSAVs used in this study were obtained from the reanalysis derived data (Kalnay et al. 1996) of the National Centers
Table 1. Identified predictors of May-June-July (MJJ) and August-September-October (ASO) rainfall by the correlation maps. SAT: surface air temperature $T_{i}$ SLP: sea level pressure $T_{i} u$ and $v$ : surface zonal and meridional wind, respectively

\begin{tabular}{|c|c|c|c|}
\hline \multirow[t]{2}{*}{ Predictor } & \multirow[t]{2}{*}{ Region } & \multicolumn{2}{|c|}{ Identified region } \\
\hline & & ${ }^{\circ} \mathrm{N}$ & ${ }^{\circ} \mathrm{E}$ \\
\hline \multicolumn{4}{|c|}{ MJJ rainfall } \\
\hline SAT & Northern Thailand & 20.0 & $97.5-102.5$ \\
\hline SLP & Gulf of Thailand & $7.5-10.0$ & $102.5-107.5$ \\
\hline$u$ & $\begin{array}{l}\text { Equatorial Indian } \\
\text { Ocean }\end{array}$ & 0 & $82.5-87.5$ \\
\hline$V$ & $\begin{array}{l}\text { Eastern equatorial } \\
\text { Pacific Ocean }\end{array}$ & $0-2.5$ & $172.5-175.0$ \\
\hline \multicolumn{4}{|c|}{ ASO rainfall } \\
\hline SAT & South China Sea & $2.5-5.0$ & $107.5-110.0$ \\
\hline SLP & Northern Thailand & $17.5-20.0$ & $97.5-100.0$ \\
\hline$u$ & Gulf of Thailand & 10.0 & $100.0-102.5$ \\
\hline$V$ & Andaman Sea & 10.0 & $95.0-97.5$ \\
\hline
\end{tabular}

for Environmental Prediction (NCEP/NOAA). With a grid resolution of $2.5^{\circ}$ longitude $\times 2.5^{\circ}$ latitude, the monthly means from 1948-2007 of 4 variables averaged over the identified regions were used to determine the variability of predictors.

\subsubsection{GCM data and climate change scenarios}

The GCM data used in this study are presented in the IPCC Third Assessment Report (TAR; IPCC 2001). The GCM selection was based on the availability of all 4 predictors. From Table 2, we selected a model of the Geophysical Fluid Dynamics Laboratory (GFDL), namely GFDL-R30, which provides simulated data of all identified predictors. The GFDL-R30 is a coupled atmosphere-ocean general circulation model (AOGCM), in which the atmospheric component covers 7680 grids with a gridded resolution of $3.75^{\circ}$ longitude $\times 2.25^{\circ}$ latitude, and it has 14 vertical levels. The ocean component has $196 \times 80$ global grids of horizontal resolution (i.e. $3.75^{\circ}$ longitude $\times$ $1.125^{\circ}$ latitude) and 18 spaced vertical levels (Delworth et al. 2002). The model simulates conditions of doubling atmospheric $\mathrm{CO}_{2}$ by 2100. The gridded data of GFDL-R30 available from 1961-2100 are provided by the IPCC Data Distribution Centre (IPCCDDC 2009). To determine the effects of climate change on pre-monsoon (MJJ) and monsoon (ASO) season rainfall in the study basin, the gridded data of predictors simulated by GFDL-R30 under 2 IPCC emission scenarios, i.e. A2 and B2, were used. The monthly gridded data of 4 predictors (i.e. SAT, SLP, $u$, 
Table 2. Availability of data $(\bullet)$ from the general circulation models associated with the identified predictors. SAT: surface air temperature; SLP: sea level pressure; $u$ and $v$ : surface zonal and meridional wind, respectively (values indicate vertical at which wind data are available)

\begin{tabular}{|c|c|c|c|c|}
\hline Scenario & SAT & SLP & $u$ & $V$ \\
\hline \multicolumn{5}{|c|}{ ECHAM4/OPY3 } \\
\hline $\mathrm{A} 2$ & $\bullet$ & $\bullet$ & & \\
\hline B2 & & & $\bullet$ & $\bullet$ \\
\hline \multicolumn{5}{|l|}{ HADCM3 } \\
\hline $\mathrm{A} 2$ & - & $\bullet$ & $10 \mathrm{~m}$ & $10 \mathrm{~m}$ \\
\hline $\mathrm{A} 2 \mathrm{~b}$ & $\bullet$ & & $10 \mathrm{~m}$ & $10 \mathrm{~m}$ \\
\hline $\mathrm{A} 2 \mathrm{C}$ & $\bullet$ & & $10 \mathrm{~m}$ & $10 \mathrm{~m}$ \\
\hline B2 & $\bullet$ & $\bullet$ & $10 \mathrm{~m}$ & $10 \mathrm{~m}$ \\
\hline \multicolumn{5}{|c|}{ CSIRO-Mk2 } \\
\hline A1 & - & - & $10 \mathrm{~m}, 200+\mathrm{hPa}$ & $10 \mathrm{~m}, 200+\mathrm{hPa}$ \\
\hline A2 & $\bullet$ & $\bullet$ & $10 \mathrm{~m}, 200+\mathrm{hPa}$ & $10 \mathrm{~m}, 200+\mathrm{hPa}$ \\
\hline B1 & - & - & $10 \mathrm{~m}, 200+\mathrm{hPa}$ & $10 \mathrm{~m}, 200+\mathrm{hPa}$ \\
\hline B2 & $\bullet$ & • & $10 \mathrm{~m}, 200+\mathrm{hPa}$ & $10 \mathrm{~m}, 200+\mathrm{hPa}$ \\
\hline \multicolumn{5}{|c|}{ NCAR-CSM } \\
\hline A2 & $\bullet$ & $\bullet$ & & \\
\hline \multicolumn{5}{|c|}{ NCAR-PCM } \\
\hline $\mathrm{A} 1 \mathrm{~b}$ & $\bullet$ & $\bullet$ & $10 \mathrm{~m}$ & $10 \mathrm{~m}$ \\
\hline A2 & $\bullet$ & $\bullet$ & $10 \mathrm{~m}$ & $10 \mathrm{~m}$ \\
\hline B2 & $\bullet$ & $\bullet$ & $10 \mathrm{~m}$ & $10 \mathrm{~m}$ \\
\hline \multicolumn{5}{|c|}{ GFDL-R30 } \\
\hline $\mathrm{A} 2$ & $\bullet$ & $\bullet$ & - & $\bullet$ \\
\hline B2 & $\bullet$ & $\bullet$ & $\bullet$ & - \\
\hline \multicolumn{5}{|l|}{ CGCM2 } \\
\hline $\mathrm{A} 2$ & $\bullet$ & • & $10 \mathrm{~m}, 200+\mathrm{hPa}$ & $10 \mathrm{~m}, 200+\mathrm{hPa}$ \\
\hline B2 & $\bullet$ & • & $10 \mathrm{~m}, 200+\mathrm{hPa}$ & $10 \mathrm{~m}, 200+\mathrm{hPa}$ \\
\hline \multicolumn{5}{|c|}{ CCSR/NIES AGCM+CCSR OGCM } \\
\hline A1 & $\bullet$ & $\bullet$ & $200+\mathrm{hPa}$ & $200+\mathrm{hPa}$ \\
\hline $\mathrm{A} 1 \mathrm{Fl}$ & $\bullet$ & $\bullet$ & $200+\mathrm{hPa}$ & $200+\mathrm{hPa}$ \\
\hline $\mathrm{A} 1 \mathrm{~T}$ & $\bullet$ & • & $200+\mathrm{hPa}$ & $200+\mathrm{hPa}$ \\
\hline $\mathrm{A} 2$ & $\bullet$ & $\bullet$ & $200+\mathrm{hPa}$ & $200+\mathrm{hPa}$ \\
\hline B1 & • & • & $200+\mathrm{hPa}$ & $200+\mathrm{hPa}$ \\
\hline B2 & $\bullet$ & • & $200+\mathrm{hPa}$ & $200+\mathrm{hPa}$ \\
\hline
\end{tabular}

and $v$ ) from 1961-2100 were obtained corresponding to the regions shown in Table 1. Subsequently, the average values over the selected grids were estimated and used to develop a stochastic statistical model.

\subsection{Modified $k$-nearest neighbor (k-nn) model}

\subsubsection{Combination cases of the predictors}

For $k$ multiple independent variables, there are $2^{k}-1$ combination cases. An optimal subset composed of a minimum number of mutually exclusive variables is selected by the model selection method to avoid redundancy of predictors. The criteria functions used to select 1 combination set out of $2^{k}-1$ cases include cross validation (CV), likelihood, and the Akaike information criterion (AIC). The generalized cross validation (GCV) with the leave-one-out technique was applied in this study to select an optimal subset. The GCV estimates the error from a developed regression by Eq. (1). The best combination is selected corresponding to the minimum GCV which indicates the least error from the developed regression using a minimum number of predictors.

$$
\mathrm{GCV}=\frac{\sum_{i=1}^{n} \frac{\left(y_{i}-y_{i}^{\prime}\right)^{2}}{n}}{(1-m / n)^{2}}
$$

where $y_{i}$ is observed data at the dropped point $\left(x_{i}\right)$ based on the leave-one-out technique, $y_{i}^{\prime}$ is the estimation from the developed regression at $x_{i}, n$ is the total number of data, and $m$ is the number of independent variables or predictors used to fit the regression.

\subsubsection{Model structure}

The modified $k$-nn model is a nonparametric stochastic approach that is modified to have functions for a locally fitting regression (Gangopadhyay et al. 2005, Sharif \& Burn 2007) and stochastic forecasting or resample of dependent variables, e.g. seasonal rainfall (Prairie et al. 2006, Podestá et al. 2009, Eum et al. 2010). The modified $k$-nn model locally captures the relationships between dependent $(y)$ and independent variables $\left(x_{1}, x_{2}, x_{3}, \ldots, x_{m}\right)$ at a given point by a number of its neighbors. Two parameters, i.e. size of neighbors $(k)$ and order of polynomials $(p)$, are estimated by the objective functions such as GCV as shown in Eq. (2):

$$
\operatorname{GCV}(k, p)=\frac{\sum_{i=1}^{n} \frac{e_{i}^{2}}{n}}{(1-m / n)^{2}}
$$

where $e_{i}$ is the error of the fitting regression, $n$ is the number of data points, and $m$ is the number of multivariate independent variables.

The regression is fitted locally by the obtained $k$ and $p$ which are associated with the minimum GCV. Subsequently, based on the developed regression, the dependent variables are estimated and called the mean estimations. The residuals $\left(e_{i}\right)$ are also computed. In terms of stochastic simulation, the modified $k$-nn model estimates the mean estimation $\bar{y}_{\text {new }}$ at a new point of independent variables $\left(x_{n e w}\right)$ for which the forecasting is required. Then, an ensemble is 
obtained by adding a residual $\left(e_{i}\right)$ to $\bar{y}_{\text {new }}$. A residual is randomly selected from the $k$-nearest neighbors of $x_{\text {new }}$ where $k$ is the size of neighbors that can be different from $k$ for the fitting regression. In practice, $k$ is estimated by $\sqrt{n-1}$. The random selection of residuals applies a weight function as shown in Eq. (3), which gives less weight to the farthest neighbor and more weight to the nearest neighbor.

$$
W(j)=\frac{1 / j}{\sum_{i=1}^{k}(1 / i)}
$$

where $W(j)$ is the weight value of a neighbor of $x_{\text {new }}$ where the distance between $x_{\text {new }}$ and this neighbor falls in the $j$ th rank.

The distance $(d)$ from a neighbor to $x_{\text {new }}$ is calculated by the Euclidean distance as shown in Eq. (4).

$$
d_{i}=\sqrt{\sum_{j=1}^{m}\left(x_{n e w, j}-x_{i, j}\right)^{2}}
$$

where $i=1,2,3, \ldots, n$, and $m$ is the number of multivariate independent variables.

By repeating the random selection of residuals, $N$ simulating ensembles at a forecasting point are obtained, e.g. in this case 300 ensembles each of MJJ and ASO rainfall in a simulation year.

The fitting regression from the modified $k$-nn model developed to capture the relationships between summer monsoon rainfall during MJJ and ASO in the Ping River Basin and predictors (i.e. SAT, SLP, $u$ and $v$ ) using GFDL-R30 data from 1961-2007 under climate change scenarios is assumed to be valid for recent climate and future changing climate.

\subsubsection{Model evaluation}

The leave-one-out cross validation was applied to evaluate the performance of the modified $k$-nn model. Based on this technique, an observation is removed from the data sets of dependent and independent variables. The regression is then fitted using the remaining data as the training set. At the eliminated point, the estimation is calculated by the developed regression and compared to the observed data. The validation was applied to all points of data from 1961-2007. It was also done separately for each season (MJJ and ASO) and scenario (A2 and B2). Furthermore, 2 criteria adopted to evaluate the modified $k$-nn model included the correlation coefficient $(r)$ and likelihood skill score (LLH). The correlation coefficient can measure a linear correlation between observations and simu- lations. For a given year, the median rainfall was estimated from 300 rainfall ensembles which were obtained from the modified $k$-nn model. Subsequently, the correlation between observed and modeled rainfall during 1961-2007 was calculated. The significant level of correlation is estimated by Fisher's transformation $\left(z^{\prime} ;\right.$ Haan 2002) as shown in Eq. (5). The distribution of correlations, which may not follow a Gaussian distribution, is converted to a normal distribution using $z^{\prime}$. The value of $z^{\prime}$ is then used to compare to $z$ of the standard normal distribution to obtain the significance level (p) of a correlation coefficient.

$$
z^{\prime}=0.5 \ln \frac{1+r}{1-r}
$$

In terms of LLH, the likelihood can evaluate a model on capturing the probability density function (PDF) of the observations. The first step of LLH calculation is to divide the climatological data into 3 categories, i.e. in this case at the 33rd and 67 th percentiles. Rainfall below the 33rd percentile was defined as below-normal rainfall, whereas rainfall above the 67th percentile was considered above-normal rainfall. The categorical probabilities of historical data in each category are thus 1/3. Subsequently, from the modified $k$-nn model, the $N$ ensembles in a given year (i.e. 300 ensembles in this case) were divided into 3 categories at the same thresholds of climatology. The categorical probabilities of ensembles in a given year, which are the proportion of ensemble members falling in each category, were computed separately for each season of rainfall and each year from 19612007. LLH of a given year was estimated as per Eq. (6):

$$
\mathrm{LLH}=\frac{\prod_{t=1}^{n} \hat{P}_{j, t}}{\prod_{t=1}^{n} P_{c j, t}}
$$

where $n$ is the number of years, $j$ is the category of an observation in Year $t, \hat{P}_{j, t}$ is the probability of ensembles for Category $j$ in Year $t_{i} \hat{P}_{j, t}=\left(\hat{P}_{1, t} \hat{P}_{2, t} \hat{P}_{3, t} \ldots, \hat{P}_{k, t}\right)$, for which $k$ is the number of categories (i.e. 3), and $P_{c j, t}$ is the climatology probability of Category $j$ in Year $t$.

The LLH ranges from 0.0 to +3.0 , which is the number of categories. The value of 0.0 indicates an inability to capture the PDF of the observation, whereas a value greater than +1.0 indicates a better performance than climatology. Perfect performance of the model is shown by a score of +3.0 . 


\subsubsection{Probability density function}

The PDF can be developed from $N$ ensembles simulated by the modified $k$-nn model. Non-exceedence and exceedence probabilities of extreme events, e.g. dry and wet, are then estimated from the PDF based on the defined thresholds of events. The probabilities of extreme events are a useful tool in decision making to manage water resources, plan agricultural practices, operate reservoirs, and develop insurance policies. In this case, dry conditions of MJJ (ASO) rainfall were defined as rainfall below the 20th percentile, i.e. 381.7 (498.2) mm, which was estimated by the observed MJJ (ASO) rainfall during 1950-2007. On the other hand, wet conditions of MJJ (ASO) rainfall were defined as rainfall above the 80th percentile, i.e. 528.9 (624.8) $\mathrm{mm}$. The rainfall that did not fall into either category was denoted as normal. The effects of climate change on pre-monsoon (MJJ) and monsoon (ASO) season rainfall in the Ping River Basin during 2011-2100 are presented in terms of dry and wet occurrence along with the non-exceedence and exceedence probabilities of events.

\section{RESULTS AND DISCUSSION}

\subsection{Characteristics of the GFDL-R30}

\subsubsection{Performance}

The performance of GFDL-R30 was evaluated by the following statistical criteria: mean $(\bar{x})$, and standard deviation (SD), coefficient of determination $\left(\mathrm{R}^{2}\right)$, and normalized root mean square error (NRMSE). The monthly observed data of identified predictors from NCEP/NOAA and modeled data obtained from GFDL-R30 during 1961-2007 were used to estimate all criteria. From Fig. 4a, the GFDL-R30 under A2 and B2 was unable to capture the $\bar{x}$ of observed SAT, SLP, $u$, and $v$, with the exception of the $\bar{x}$ of $V$, which is associated with the ASO rainfall predictor. The $\bar{X}$ of observed $v$ from 1961-2007 was estimated as $0.64 \mathrm{~m} \mathrm{~s}^{-1}$, whereas the $\bar{X}$ of modeled $v$ under A2 (B2) was calculated as $0.68(0.66) \mathrm{m} \mathrm{s}^{-1}$, which falls into the $95 \%$ con-
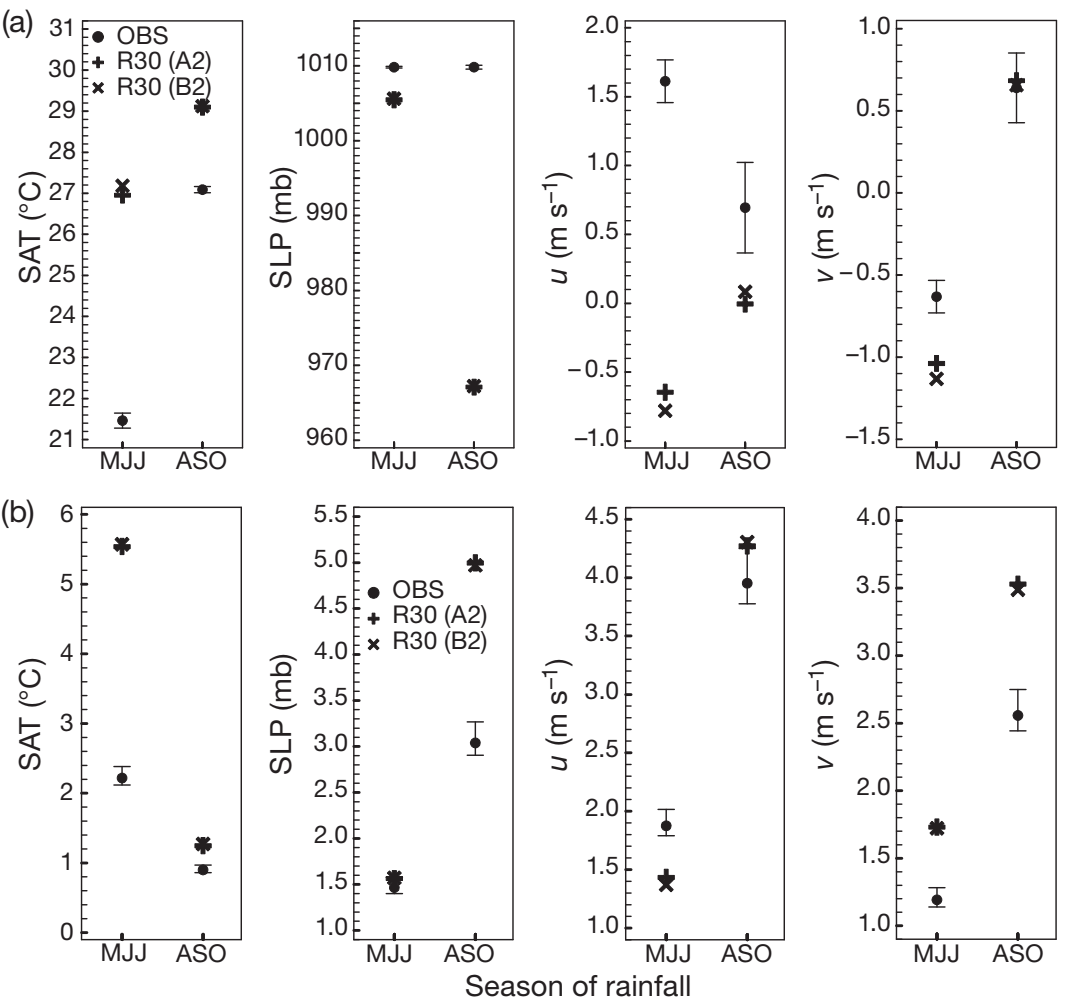

Fig. 4. Statistics of the observed and GFDL-R30 predictors of May-June-July (MJJ) and August-September-October (ASO) rainfall: (a) mean $(\bar{x})$ and (b) SD; the $95 \%$ confidence intervals for $\bar{x}$ and SD are presented by the vertical extending from the $\bar{x}$ and SD of climatology. SAT: surface air temwinds, respectively

fidence intervals (CI) for $\bar{x}$ of the observed $v$. In terms of SD (Fig. 4b), only the SD of modeled SLP corresponding to the predictors of MJJ rainfall fell into the 95\% CI for SD of the 1961-2007 observed SLP. Fig. 5 shows the $\mathrm{R}^{2}$ between observed and simulated pre-
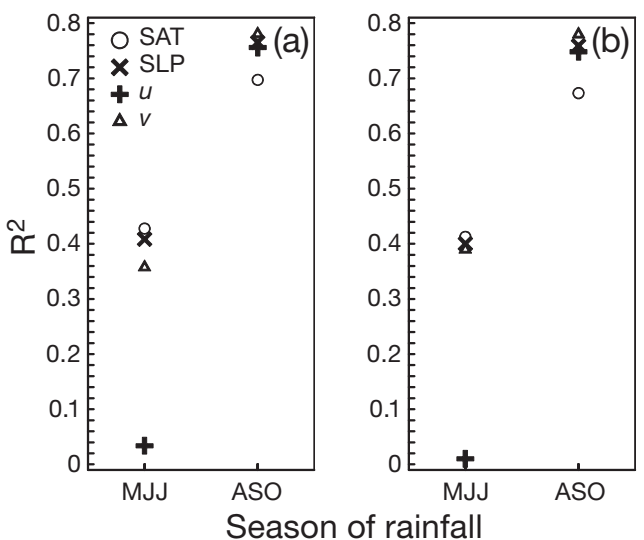

Fig. 5. $\mathrm{R}^{2}$ between observed and GFDL-R30 predictors of May-June-July (MJJ) and August-September-October (ASO) rainfall, under the (a) A2 and (b) B2 scenarios. SAT: surface air temperature; SLP: sea level pressure; $u$ and $v$ : surface zonal and meridional winds, respectively 


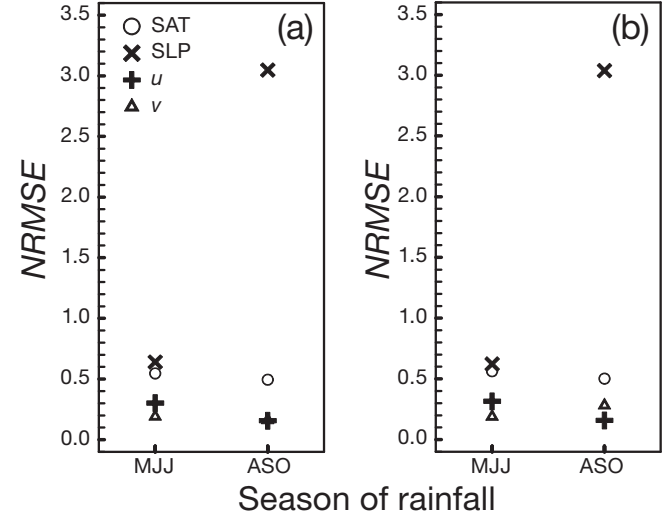

Fig. 6. Normalized root mean square error (NRMSE) from GFDL-R30 predictions of May-June-July (MJJ) and AugustSeptember-October (ASO) rainfall, under the (a) A2 and (b) B2 scenarios. SAT: surface air temperature; SLP: sea level pressure $; u$ and $v$ : surface zonal and meridional winds, respectively
A2 and B2 scenarios. For the predictors of MJJ rainfall, the annual observed SAT anomalies (Fig. 7), which were estimated with respect to observed SAT averaged from 1961-1990, showed that the temperatures over northern Thailand (see also Table 1) during the 1990s were warmer than in the earlier century. The annual observed SAT from 1948-2007 tended to increase by $0.41^{\circ} \mathrm{C}$ century $^{-1}$. It is lower than the trend in global surface temperatures, which indicate a range of 1 to $2^{\circ} \mathrm{C}$ century ${ }^{-1}$ (IPCC 2007, Jenkins et al. 2008, Hansen et al. 2010). Moreover, by the end of the 21st century, the GFDL model suggests that the SAT over this region will be 2 to $5^{\circ} \mathrm{C}$ warmer with increasing trends of 3.47 and $1.93^{\circ} \mathrm{C}_{\text {century }}{ }^{-1}$ under A2 and B2, respectively. Both trends were significant at the $99.9 \%$ confidence level by Student's $t$ test (Haan 2002). The variability of temperature was not only observed in terms of magnitude but also dictors obtained from GFDL-R30. Comparing between $\mathrm{R}^{2}$ associated with the MJJ and ASO rainfall predictors, the greater $\mathrm{R}^{2}$ correspond to all 4 predictors of ASO rainfall. Hence, based on the $\mathrm{R}^{2}$, better performance of GFDL-R30 was observed in the ASO rainfall predictors under both scenarios of climate change. According to A2 (B2), 70-78\% (67-78\%) of the observed data of ASO rainfall predictors can be explained by the modeled results from GFDL-R30. As expected, the NRMSEs were consistent with the $\mathrm{R}^{2}$, except the NRMSE of SLP. The NRMSEs of SAT, $u$, and $v$ under A2 (Fig. 6a), varying from 0.16 to 0.49 , correspond to the ASO rainfall predictors, which were slightly lower than those of the MJJ rainfall predictors. Moreover, from Fig. 6b, the NRMSEs with respect to B2 were consistent with A2, except the NRMSE of $v$.

\subsubsection{Annual variability and trends in LSAVs}

The variability of LSAVs used as predictors of MJJ and ASO rainfall was determined by the observed data from 1948-2007 provided by NCEP and the projected data from 20112100 simulated by GFDL-R30 under

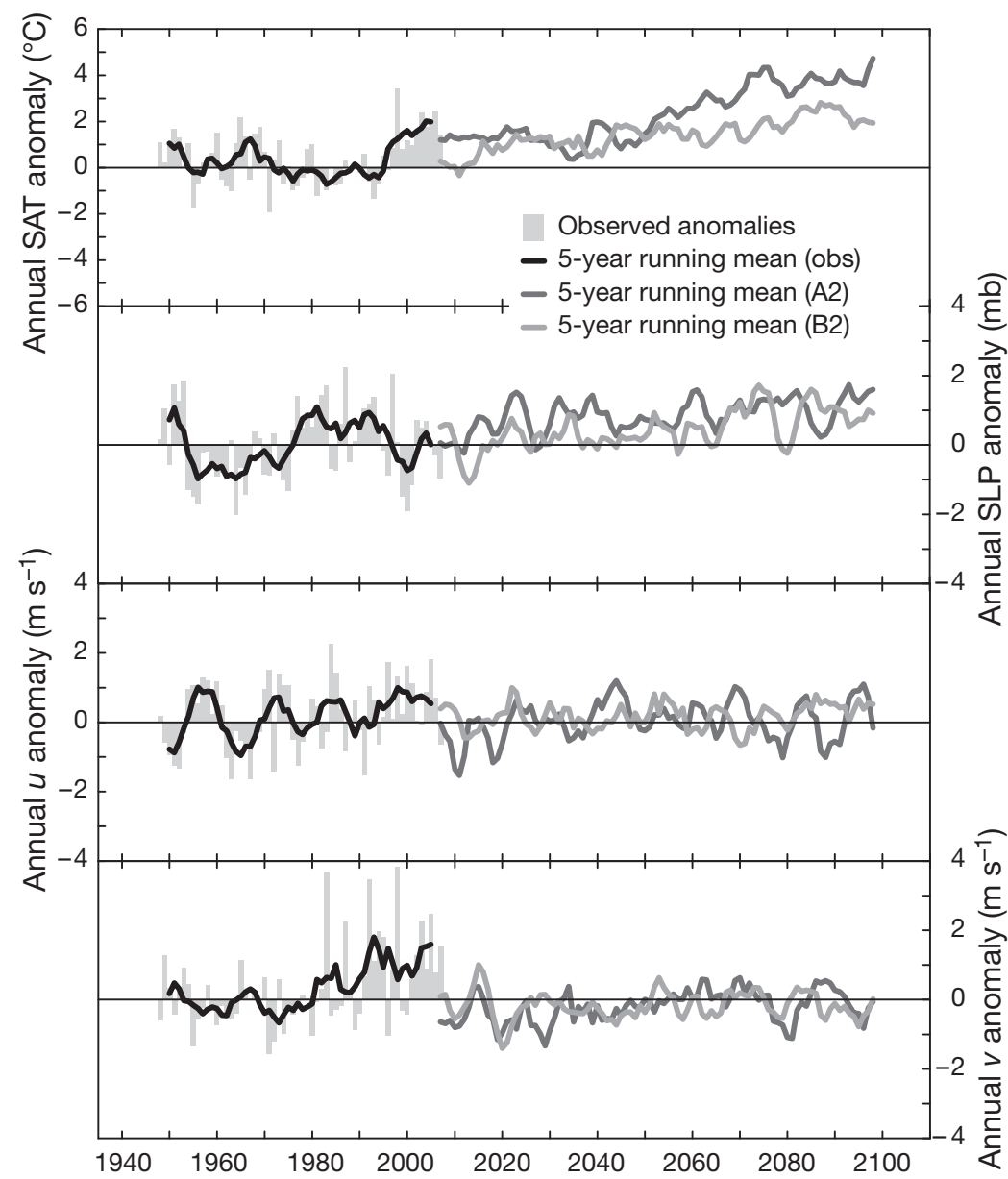

Fig. 7. Annual anomalies of 4 observed (1948-2007) predictors of May-JuneJuly (MJJ) rainfall, and the 5 yr running mean from observed and GFDL-simulated (2011-2100) data; anomalies are estimated with respect to observed or model-simulated 1961-1990 average values. SAT: surface air temperature; SLP: sea level pressure; $u$ and $v$ : surface zonal and meridional winds, respectively 
temporal aspect. The summer season in Thailand will be longer by a few months and vice versa for the winter season (Chinvanno 2009). On the other hand, from 1948-2007, the annual observed SLP over the Gulf of Thailand shows an increasing trend by 0.32 millibar (mb) century ${ }^{-1}$. Below-normal SLP (i.e. negative anomalies) was found during pre-1980 and vice versa during post-1980. However, the projected SLP from the GFDL model tends to gradually increase by $0.40(0.54)$ mb century $^{-1}$ under A2 (B2) with a significance at the $99.0 \%(99.5 \%)$ confidence level. In terms of $u$ over the equatorial Indian Ocean and $v$ over the eastern equatorial Pacific Ocean, the observed wind velocities during the 1990s were greater than in the previous century, with increasing trends by $0.87 \mathrm{~m} \mathrm{~s}^{-1}$ century $^{-1}$ (i.e. significant at the $90.0 \%$ confidence level) and $0.76 \mathrm{~m} \mathrm{~s}^{-1}$ century $^{-1}$ (i.e. significant at the $99.5 \%$ confidence level), respectively. However, from the GFDL-R30 associated with A2 (B2), the annual wind velocities during 20112100 show anomalies with slightly increasing trends by $0.03(0.08) \mathrm{m} \mathrm{s}^{-1}$ century $^{-1}$ for $u$ and $0.18(0.03) \mathrm{m} \mathrm{s}^{-1}$ century $^{-1}$ for $v$.

For the predictors of ASO rainfall (Fig. 8), the observed temperatures over the South China Sea (see also Table 1) during post-1980 are warmer than pre-1980 with an increasing trend of $2.09^{\circ} \mathrm{C}_{\text {century }}{ }^{-1}$, which is significant at the $99.9 \%$ confidence level. Due to climate change, the projected SAT from GFDL-R30 showed that during 20112100, the temperatures over the South China Sea will become warmer with increasing trends of 2.57 and $1.65^{\circ} \mathrm{C}$ century $^{-1}$ under A2 and B2 scenarios, respectively. These trends are also significant at the $99.9 \%$ confidence level. In addition, by the end of the 21 st century, the annual temperature anomalies over this region will range from +9 to $+10^{\circ} \mathrm{C}$. For the SLP over northern Thailand, the annual observed data from 1948-2007 indicate an increasing trend of $3.03 \mathrm{mb}$ century ${ }^{-1}$, which is significant at the $99.9 \%$ confidence level. During pre- (post-)1980, below- (above) normal SLP was found, which is consistent with the SLP of MJJ rainfall predictors over the Gulf of Thailand. From 2011-2100, an increasing trend of projected SLP simulated by GFDL-R30 under A2 (B2) is significant at the 99.9\% (99.5\%) confidence level with $0.83(0.71) \mathrm{mb}_{\text {century }}{ }^{-1}$. On the other hand, the observed $u$ over the Gulf of Thailand showed a deceasing trend by $0.18 \mathrm{~m} \mathrm{~s}^{-1}$ century $^{-1}$. Likewise, the GFDL-R30 indicates that the $u$ will decrease (increase) with a trend of 0.14 (0.18) $\mathrm{m}$ $\mathrm{s}^{-1}$ century $^{-1}$ under A2 (B2). For the $v$ over the Andaman Sea, the observed data indicate a decreasing trend (significant at the $99.9 \%$ confidence level) by $1.00 \mathrm{~m} \mathrm{~s}^{-1}$ century ${ }^{-1}$. The anomalies of wind velocity suggest that the annual winds during pre-1960 were stronger than post-1960. Under the A2 (B2) scenario of climate change, the GFDL-R30 indicated a significant decreasing trend in $v$ at the $90.0 \%$ (99.0\%) confidence level with $0.20(0.29) \mathrm{m} \mathrm{s}^{-1}$ century $^{-1}$ during 2011-2100.

Therefore, temporal variability of LSAVs, which are identified as the potential predictors of MJJ and ASO rainfall, was observed. The decadal variability during pre- and post-1980 is consistent with the non-

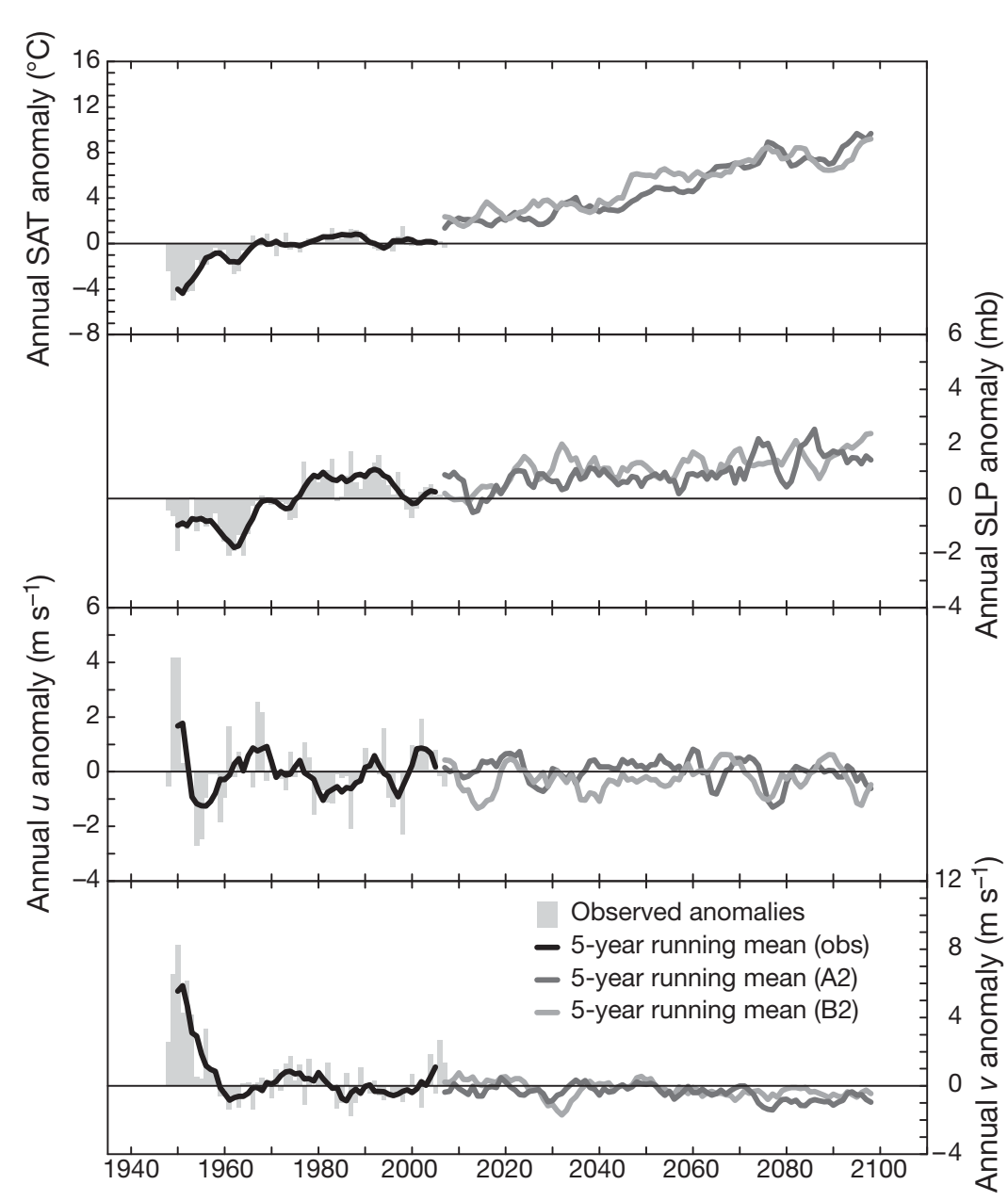

Fig. 8. Annual anomalies of 4 observed (1948-2007) predictors of AugustSeptember-October (ASO) rainfall. Other details as in Fig. 7 
linear relationships between LSAVs and summer monsoon rainfall which are found in the correlation maps (Singhrattna et al. in press). The decadal variability and the nonlinear relationships are also corroborated by Singhrattna et al. (2005b). Via the Walker circulation, temporal variability is influenced by the sea surface temperature anomalies, which have shifted from the dateline to the eastern equatorial Pacific Ocean during recent decades. Due to climate change, the LSAVs also indicate annual variability and significant trends during 2011-2100. With significance at the $99.9 \%$ confidence level, the annual SAT tends to increase ranging from 1.65 to $3.47^{\circ} \mathrm{C}$ century $^{-1}$. The annual SLP also tends to increase varying from 0.40 to $0.83 \mathrm{mb}^{\text {century }}{ }^{-1}$. However, the trends of annual $u$ and $v$ are dependent upon the identified regions and scenarios of climate change. By atmospheric-oceanic circulation, the effects of climate change on the annual variability of LSAVs may influence the fluctuations of rainfall and frequencies of extreme events, i.e. dry and wet during pre-monsoon and monsoon seasons in the study basin. Hence, based on the relationships between rainfall and identified LSAVs, the modified $k$-nn model was developed to determine the variability of rainfall due to climate change.

\subsection{Model performance of the modified $k$-nn model}

\subsubsection{Optimal combination cases of predictors}

The GCV was adopted to select the optimal subsets of predictors which consisted of mutually exclusive independent variables. With respect to 4 identified predictors each of MJJ and ASO rainfall, there were 15 combination cases. The GCVs were estimated separately for MJJ and ASO rainfall predictors using the 1961-2007 simulated LSAVs by GFDL-R30 under $\mathrm{A} 2$ and $\mathrm{B} 2$ as the independent variables and the 1961-2007 observed rainfall as the dependent variable. The GCV of each combination case was also calculated under a condition of varying lead periods of predictors from 4 to 15 mo prior to the start of the rainfall season. Based on the minimum GCV, a best combination case was selected. Associated with A2, the optimal combination of MJJ (ASO) rainfall predictors consisted of the SLP and $u$ ( $u$ and $v$ ) during November-December-January, NDJ (April-MayJune, AMJ) which had a 6 (4) mo lead time. On the other hand, the selected subsets corresponding to B2 are the SLP for MJJ rainfall predictors, and the SAT and SLP for ASO rainfall predictors. The lead times of predictors were 6 and 14 mo, i.e. during NDJ and June-July-August (JJA), respectively.

\subsubsection{Model evaluation}

The modified $k$-nn model was evaluated using correlation ( $r$ ) and likelihood (LLH). With leave-one-out cross validation, all points of data from 1961-2007 were used to evaluate the models for MJJ and ASO rainfall. The median rainfall in a given year was computed from 300 ensembles and subsequently used to calculate the correlations. Under A2, the correlation between 1961-2007 observed and modeled MJJ (ASO) rainfall was estimated at 0.41 (0.51), which is significant at the $99.0 \%$ (99.9\%) confidence level by Fisher's transformation. The median LLH from the simulation of 1961-2007 MJJ rainfall was 1.12, whereas the median LLH from the simulation of ASO rainfall was 1.23 . Hence, with respect to A2, the performance of the modified $k$-nn model in capturing the PDF of MJJ and ASO rainfall was better than that of the climatology. On the other hand, the correlation between observed and modeled MJJ rainfall corresponding to B2 was calculated to be 0.17. For ASO rainfall was better, the correlation was estimated to be 0.38, which is significant at the $99.0 \%$ confidence level. Moreover, the median LLH associated with MJJ (ASO) rainfall was estimated as $1.12(0.79)$. Therefore, under the B2 scenario, better performance in capturing the PDF of historical data compared to the climatology was found in the model for MJJ rainfall.

As a result, the modified $k$-nn model developed for MJJ rainfall under A2 (B2) used SLP and $u$ (SLP) during NDJ as the predictors. At the $99.0 \%$ confidence level, the model under A2 indicated a significant correlation between observed and modeled MJJ rainfall during 1961-2007. Furthermore, the models under both scenarios of climate change captured the PDF of observed MJJ rainfall with LLH scores of 1.12, which was better than the climatology. On the other hand, the modified $k$-nn model with the predictors of $u$ and $V$ (SAT and SLP) during AMJ (JJA) was developed to simulate the ASO rainfall under A2 (B2). The correlations between observed and modeled ASO rainfall were estimated at 0.51 (i.e. significant at the $99.9 \%$ confidence level) and 0.38 (i.e. significant at the 99.0\% confidence level) associated with A2 and B2, respectively. In terms of $\mathrm{LLH}$, the modified $k$-nn model under A2 showed better performance in capturing the PDF of historical data than the climatology. 


\subsection{Effects of climate change on seasonal rainfall}

\subsubsection{Annual variability and trend}

We estimated the median rainfall from 300 rainfall ensembles in a given year simulated by the modified $k$-nn model. Subsequently, the seasonal rainfall anomalies from 2011-2100 were calculated with respect to the observed 1961-1990 average seasonal rainfall. The trends of anomalies are shown in Fig. 9. From the observed MJJ rainfall during 1950-2007, a maximum of $651.9 \mathrm{~mm}$ and a minimum of $254.0 \mathrm{~mm}$ were found in 1950 and 1997, respectively. The decreasing trend was estimated to be $0.69 \mathrm{~mm} \mathrm{yr}^{-1}$. The rainfall anomalies estimated with respect to the observed 1961-1990 average MJJ rainfall ranged from -2.1 to $+2.5 \mathrm{~mm}$. The MJJ rainfall tended to be above-normal during pre1980 and below-normal during post-1980. Under the condition of doubling atmospheric $\mathrm{CO}_{2}$ in the A2 scenario, a maximum of $759.8 \mathrm{~mm}$ and a minimum of $279.6 \mathrm{~mm}$ will be found in 2015 and 2050, respectively. Based on the simulation from 2011-2100, the MJJ rainfall will decrease by $0.11 \mathrm{~mm} \mathrm{yr}^{-1}$. With respect to the observed 1961-1990 average MJJ rainfall, abovenormal rainfall will tend to occur during the 2020s and 2070s, whereas below-normal rainfall will tend to occur during the remaining periods. The increasing trend of rainfall in particular during the 2020s is consistent with Tao et al. (2003), who presented the effects of climate change on increasing annual rainfall in Thailand, Singapore, Vietnam, and Laos. Under the B2 scenario, the maximum MJJ rainfall (600.2 $\mathrm{mm})$ will be found in

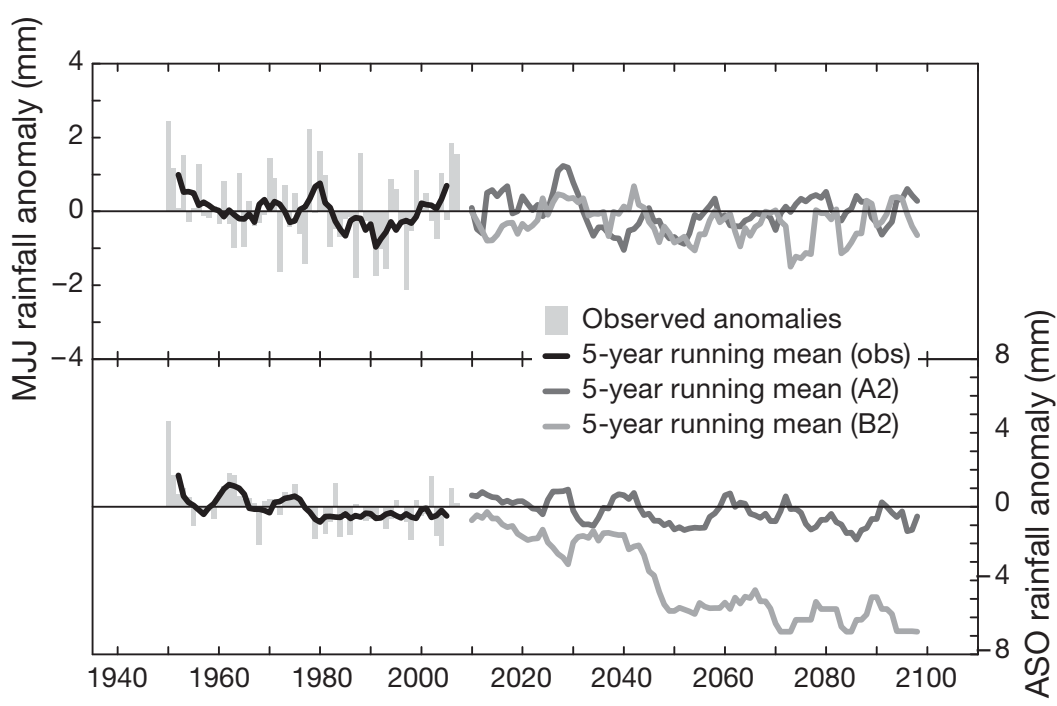

Fig. 9. Annual anomalies of observed (1950-2007) May-June-July (MJJ) and August-September-October (ASO) rainfall, and the 5 yr running mean from observed and modified $k$-nn simulated (2011-2100) rainfall; anomalies are estimated with respect to observed 1961-1990 average rainfall
2022 , corresponding to an anomaly of $+1.86 \mathrm{~mm}$. The MJJ rainfall shows a decreasing trend of $0.17 \mathrm{~mm} \mathrm{yr}^{-1}$. Under both scenarios of climate change, the decreasing trends of MJJ rainfall in the future, i.e. during 20112100 , are less than the decreasing trend during the recent period, i.e. from 1950-2007. These results suggest that climate change will have the effect of decreasing MJJ rainfall in the Ping River Basin, with a slower rate in the future than in earlier periods.

On the other hand, the observed monsoon season (ASO) rainfall from 1950-2007 indicated a maximum (minimum) of 948.3 (387.6) $\mathrm{mm}$ in 1950 (2004). A decreasing trend was estimated by $2.29 \mathrm{~mm} \mathrm{yr}^{-1}$, which was significant at the $99.5 \%$ confidence level (Fig. 9). During pre-1980, the ASO rainfall showed positive anomalies and vice versa for post-1980. This is consistent with the anomalies of pre-monsoon (MJJ) season rainfall. Under A2, the ASO rainfall indicated a maximum of $908.4 \mathrm{~mm}$ in 2027 from 90 simulation years (2011-2100), which is associated with an anomaly of $+4.13 \mathrm{~mm}$ calculated with respect to the observed 1961-1990 average ASO rainfall. From 2011-2100, a minimum of ASO rainfall by $346.4 \mathrm{~mm}$ will be found in 2095. Furthermore, with significance at the $97.5 \%$ confidence level, the ASO rainfall will decrease by $1.09 \mathrm{~mm} \mathrm{yr}^{-1}$. Under B2, the ASO rainfall simulated by the modified $k$-nn model indicated a maximum of $598.7 \mathrm{~mm}$ in 2013 with a rainfall anomaly by +0.41 mm corresponding to the observed 1961-1990 average ASO rainfall. In 2011-2100, ASO rainfall will decrease $6.16 \mathrm{~mm} \mathrm{yr}^{-1}$, significant at the $99.9 \%$ confidence level. The variability of summer monsoon rainfall during $\mathrm{MJJ}$ and $\mathrm{ASO}$ is influenced by the variations of tropical typhoons over Southeast Asia (i.e. approximately $10^{\circ} \mathrm{N}$ latitude) due to global warming (NIC 2009). The monsoon season is also expected to delay the onset date by 10 to $15 \mathrm{~d}$ (Bhaskaran \& Mitchell 1998). The fluctuations in intensity and seasonality of the monsoon are related to the atmospheric-oceanic anomalies, especially the sea surface temperature anomalies in the Pacific Ocean, i.e. El Niño and La Niña. In the 21st century, the temperature over the eastern tropical Pacific Ocean will be warmer by more than $5^{\circ} \mathrm{C}$, which can cause inconsistent trends in summer monsoon rainfall across regions of Southeast Asia (Paeth et al. 2008).

Hence, during 2011-2100, the effects of climate change on the variability of 
MJJ rainfall in the Ping River Basin indicate decreasing trends by 0.11 and $0.17 \mathrm{~mm} \mathrm{yr}^{-1}$ corresponding to A2 and B2, respectively. The decreasing trends of 2011-2100 ASO rainfall are also estimated by 1.09 and $6.16 \mathrm{~mm} \mathrm{yr}^{-1}$, respectively. Under both scenarios, the 2011-2100 MJJ rainfall will tend to decrease at a slower rate compared to the rate of the 1950-2007 observed rainfall (i.e. $0.69 \mathrm{~mm} \mathrm{yr}^{-1}$ ). On the other hand, compared to a decreasing trend of historical rainfall by $2.29 \mathrm{~mm} \mathrm{yr}^{-1}$, the ASO rainfall from $2011-$ 2100 will decrease at a slower rate under A2 but at a faster rate under $\mathrm{B} 2$.

\subsubsection{PDF of extreme events}

The medians of 300 rainfall ensembles simulated by the modified $k$-nn model were estimated. The PDF of median rainfall (from 2011-2100) was then plotted along with the PDF of historical data (from 1950-2007) as shown in Fig. 10. For MJJ (ASO) rainfall, the probabilities of dry and wet conditions were calculated from PDFs based on the thresholds at the 20th and 80th percentiles of observed rainfall, i.e. 381.7 (498.2) and 528.9 (624.8) $\mathrm{mm}$, respectively. From the climatological PDF, there was a $20 \%$ chance that MJJ rainfall is below $381.7 \mathrm{~mm}$, indicating dry conditions. However, the PDF of modeled rainfall indicated that during 2011-2100, the probability of MJJ rainfall being less than $381.7 \mathrm{~mm}$ was $26.4 \%$ (33.3\%) under A2 (B2). Moreover, from the climatological PDF, there was a $20 \%$ chance that MJJ rainfall is above $528.9 \mathrm{~mm}$ (i.e. wet condition), whereas the PDF of modeled rainfall with respect to A2 (B2) showed a probability of $16.6 \%(15.2 \%)$. On the other hand, from the PDF of rainfall ensembles associated with A2 (B2), there is a higher chance by $39.7 \%(84.5 \%)$ compared to a $20 \%$ chance from the climatological PDF showing that the ASO rainfall during 2011-2100 will be below $498.2 \mathrm{~mm}$. The PDF of 2011-2100 modeled ASO rainfall also indicated a probability of $22.0 \%(5.1 \%)$ that ASO rainfall will be above $624.8 \mathrm{~mm}$.

Considering the probabilities of extreme events in each year of simulation, the PDF of 300 rainfall ensembles was established, and the probabilities were calculated based on the thresholds at the 20th and 80th percentiles of the historical data. From Fig. 11, out of 90 simulated years (from 2011-2100) and with a high probability of occurrence $(>70 \%)$, there are 10 years indicating that the MJJ rainfall will be below $381.7 \mathrm{~mm}$ (i.e. being dry), and there are 8 years showing that the MJJ rainfall will be above

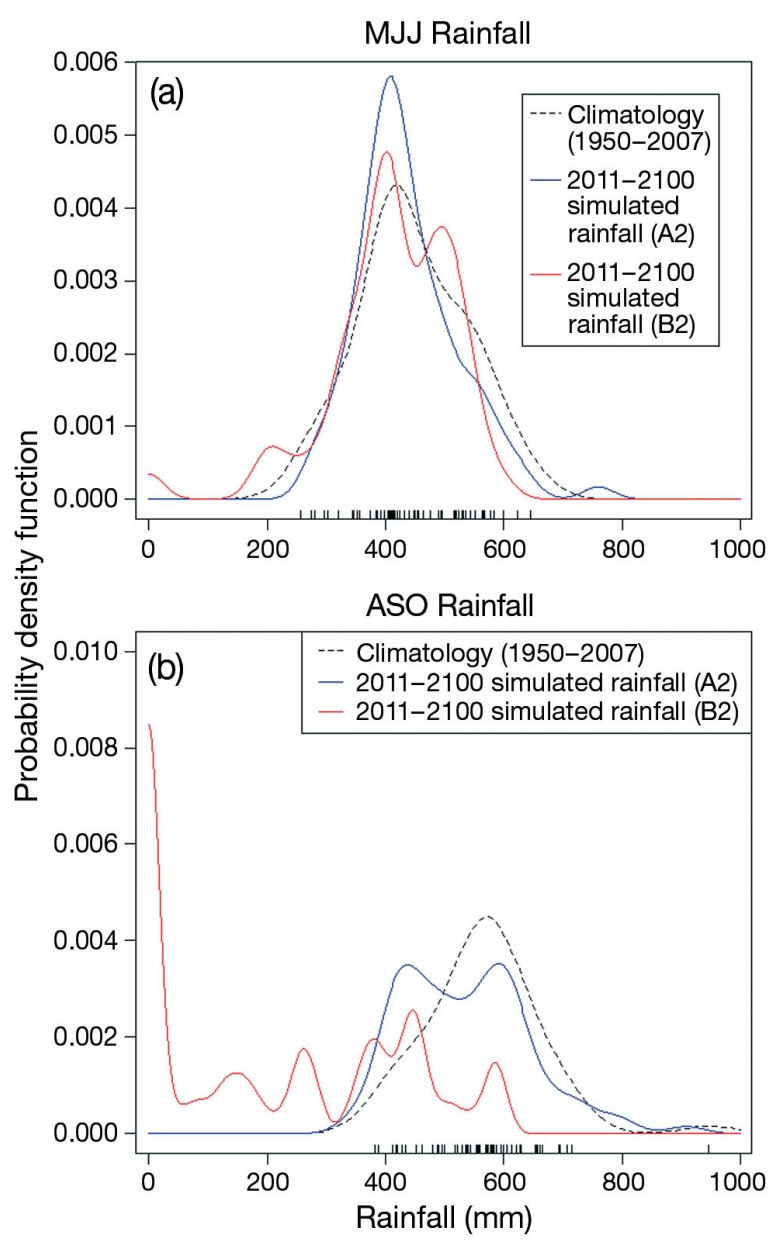

Fig. 10. Probability density function (PDF) of median rainfall from 300 ensembles simulated by the modified $k$-nn model during 2011-2100: (a) May-June-July (MJJ) rainfall and (b) August-September-October (ASO) rainfall

$528.9 \mathrm{~mm}$ (i.e. being wet) corresponding to A2. Of 8 wet years, 5 years $(2015,2029,2043,2073$, and 2079) show a chance of occurrence above $90 \%$. Under B2, with a high probability $(>70 \%)$, there are 18 years of dry MJJ rainfall, of which 9 years showed a chance $>90 \%$. The MJJ rainfall in 8 years during 2011-2100 will be above $528.9 \mathrm{~mm}$ with a chance of occurrence of only $50-60 \%$. On the other hand, with a chance $>70 \%$, there are 20 years showing that the ASO rainfall will be below $498.2 \mathrm{~mm}$ corresponding to A2, and there are 11 years indicating that the ASO rainfall will be above $624.8 \mathrm{~mm}$. Of these dry (wet) years, 7 (9) years indicate a chance of occurrence greater than $90 \%$. Associated with B2, the wet ASO rainfall with a probability of occurrence $>50 \%$ will not be observed during 2011-2100. However, the dry ASO rainfall with a chance of occurrence greater than $90 \%$ will be found in several years, in particular a long consecutive period from 2046-2100, i.e. 55 yr. 


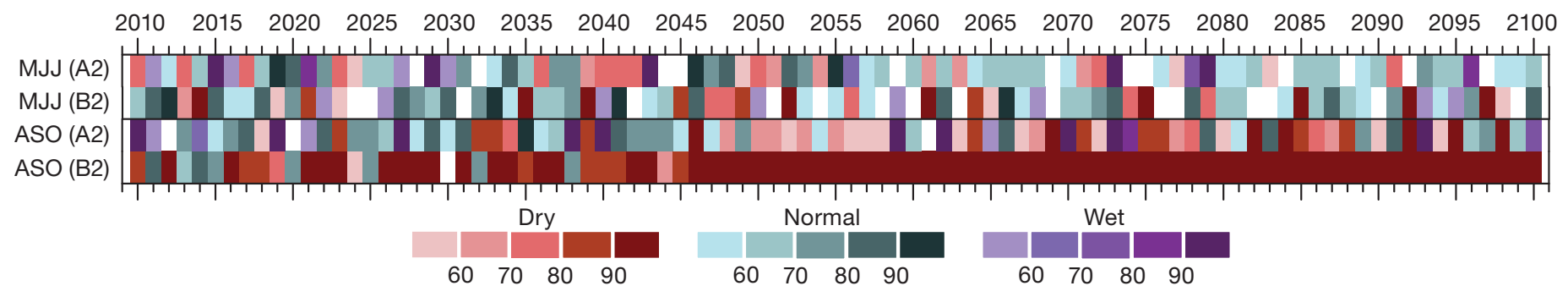

Fig. 11. Probability of dry, normal, and wet conditions of May-June-July (MJJ) and August-September-October (ASO) rainfall during 2011-2100 under the A2 and B2 scenarios of climate change

Therefore, the effects of climate change on the frequency of extreme events show that during 20112100, the MJJ rainfall conditions in the Ping River Basin have a greater (smaller) chance of being dry (wet) under both scenarios of climate change than the climatology. Under A2, low (high) MJJ rainfall will be found in 10 (8) years with a probability of occurrence more than $70 \%$. Under B2, there are 18 years of low MJJ rainfall with a probability more than $70 \%$ and 8 years of high MJJ rainfall with a chance of occurrence of only 50-60\%. In contrast, under A2, the 2011-2100 ASO rainfall indicates more chance of being dry and wet compared to the historical record. Dry (wet) ASO conditions will be observed in 20 (11) years with a probability of occurrence $>70 \%$. However, under B2, the ASO rainfall has a greater (smaller) chance of being low (high) during 2011-2100. With a chance of occurrence $>90 \%$, dry ASO rainfall conditions will be found in several years, in particular a consecutive period from 2046-2100, whereas wet ASO rainfall conditions with a probability of occurrence more than $50 \%$ will not be observed.

\section{CONCLUSIONS}

We used the modified $k$-nn model to determine the effects of climate change on summer monsoon rainfall in the Ping River Basin and downscaled the surface rainfall from large-scale atmospheric variables. The projected SAT, SLP, $u$, and $v$ from GFDL-R30 were used as the predictors of MJJ and ASO rainfall in the modified $k$-nn model. During 2011-2100, the annual SAT over northern Thailand and the South China Sea showed increasing trends ranging from 1.65 to $3.47^{\circ} \mathrm{C}$ century $^{-1}$ which were significant at the $99.9 \%$ confidence level. By the end of the 21st century, the anomalies of annual SAT will range from +2 to $+10^{\circ} \mathrm{C}$. The annual SLP over the Gulf of Thailand and northern Thailand also indicated increasing trends varying from 0.40 to $0.83 \mathrm{mb}$ century $^{-1}$. Increasing and decreasing trends of $u$ and $v$ will be observed during
2011-2100 based on the identified regions of wind and scenarios of climate change. Subsequently, due to the atmospheric-oceanic circulation, the pre-monsoon and monsoon season rainfall in the Ping River Basin is influenced by climate change not only in the variability of rainfall but also in the frequency of extreme events. Under a condition of doubling $\mathrm{CO}_{2}$ concentration by 2100 , the effects of climate change on rainfall variability indicate decreasing trends of MJJ and ASO rainfall with a slower rate than the rate obtained from the 1950-2007 observed rainfall, except the ASO rainfall under B2, which shows an accelerated decreasing trend by $6.16 \mathrm{~mm} \mathrm{yr}^{-1}$.

In terms of the effects of climate change on the frequency of extreme events, i.e. dry and wet, under both scenarios of climate change, the dry (wet) condition of rainfall showed a greater (smaller) chance of occurrence than the climatology, except the ASO rainfall under A2, which showed a greater chance of being both dry and wet during 2011-2100. With a probability of occurrence $>70 \%$, extreme events will be observed more in ASO than in MJJ. Moreover, dry conditions of MJJ and ASO rainfall will be found more than wet conditions, in particular the ASO rainfall under B2, which indicates consecutive dry years from 2046-2100. The decreasing trends of summer monsoon rainfall and increasing frequencies of dry conditions in the Ping River Basin will affect water resource planning and water-related activities, e.g. agriculture in the study basin and downstream area; consequently, the basin requires adaptation and sustainable strategies to accommodate future climate change.

Acknowledgements. We thank S. Weesakul, S.R. Perret, and $K$. Honda for their comments. We also thank the Royal Irrigation Department of Thailand, the Thailand Meteorological Department, and the Department of Water Resources for providing the data for the study. N.S. thanks the Asian Institute of Technology (Thailand) for graduate fellowships and the Department of Public Works and Town \& Country Planning for its kind support. CIRAD research funding is gratefully acknowledged. Finally, we thank the anonymous reviewers, whose comments improved the manuscript. 


\section{LITERATURE CITED}

Bhaskaran B, Mitchell JFB (1998) Simulated changes in Southeast Asian monsoon precipitation resulting from anthropogenic emission. Int J Climatol 18:1455-1462

Bronstert A (2004) Rainfall-runoff modelling for assessing impacts of climate and land-use change. Hydrol Process 18:567-570

$>$ Chen TC, Yoon JH (2000) Interannual variation in Indochina summer monsoon rainfall: possible mechanism. J Clim 13:1979-1986

Chinvanno S (2009) Future climate projection for Thailand and surrounding countries: climate change scenario of 21st century. 1st China-Thailand Joint Seminar on Climate Change, Bangkok

- Croke BFW, Merritt WS, Jakeman AJ (2004) A dynamic model for predicting hydrologic response to land cover changes in gauged and ungauged catchments. J Hydrol (Amst) 291:115-131

> Delworth TL, Stouffer RJ, Dixon KW, Spelman MJ and others (2002) Review of simulations of climate variability and change with the GFDL R30 coupled climate model. Clim Dyn 19:555-574

ESRL (Earth System Research Laboratory) (2008) Interactive plotting and analysis: linear monthly/seasonal correlations. Available at: www.esrl.noaa.gov/psd/data/correlation

Eum HI, Simonovic SP, Kim YO (2010) Climate change impact assessment using k-nearest neighbor weather generator: case study of the Nakdong River Basin in Korea. J Hydrol Eng 15:772-785

Gangopadhyay S, Clark M, Rajagopalan B (2005) Statistical downscaling using k-nearest neighbors. Water Resour Res 41:W02024 doi:10.1029/2004WR003444

Grantz K, Rajagopalan B, Clark M, Zagona E (2005) A technique for incorporating large-scale climate information in basin-scale ensemble streamflow forecasts. Water Resour Res 41:W10410 doi:10.1029/2004WR003467

Haan CT (2002) Statistical methods in hydrology, 2nd edn. Iowa State Press, Ames, IA

Hamlet AF, Huppert D, Lettenmaier DP (2002) Economic value of long-lead streamflow forecasts for Columbia River hydropower. J Water Resour Plan Manag 128: 91-101

Hansen J, Ruedy R, Sato M, Lo K (2010) Global surface temperature change. Rev Geophys 48:RG4004 doi:10.1029/ 2010RG000345

IPCC (2001) Climate change 2001: impacts, adaptation and vulnerability. Cambridge University Press, Cambridge

IPCC (2007) IPCC fourth assessment report: climate change 2007, global average temperatures. Available at: www. ipcc.ch/publications_and_data/ar4/wg1/en/tssts-3-1-1.html

IPCC-DDC (IPCC Data Distribution Centre) (2009) TAR GCM data. Available at: www.mad.zmaw.de/IPCC_ DDC/html/SRES_TAR/index.html

Jenkins GJ, Perry MC, Prior MJ (2008) The climate of the United Kingdom and recent trends. Met Office Hadley Center, Exeter

Kalnay E, Kanamitsu M, Kistler R, Collins W and others (1996) The NCEP/NCAR reanalysis 40-year project. Bull Am Meteorol Soc 77:437-471

Kanae S, Oki T, Musiake K (2001) Impact of deforestation on regional precipitation over the Indochina Peninsula. J Hydrometeorol 2:51-70

Koocheki A, Nassiri M, Soltani A, Sharifi H, Ghorbani R (2006) Effects of climate change on growth criteria and yield of sunflower and chickpea crops in Iran. Clim Res
30:247-253

Krishna Kumar K, Soman MK, Rupakumar K (1995) Seasonal forecasting of Indian summer monsoon rainfall: a review. Weather 50:449-467

Loader C (1999) Local regression and likelihood. Springer, New York, NY

Maslin M (2007) Global warming: causes, effects and the future. MBI Publishing Company LLC, Minneapolis, MN

McCabe GJ, Dettinger MD (2002) Primary modes and predictability of year-to-year snowpack variation in the western United States from teleconnections with Pacific Ocean climate. J Hydrometeorol 3:13-25

- Mitchell JFB (1989) The 'greenhouse' effect and climate change. Rev Geophys 27:115-139

> Moriondo M, Bindi M (2006) Comparison of temperature simulated by GCMs, RCMs and statistical downscaling: potential application in studies of future crop development. Clim Res 30:149-160

NASA (2010) The ups and downs of global warming. Available at: www.nasa.gov/topics/earth/features/upsDowns GlobalWarming.html

NIC (National Intelligence Council) (2009) Southeast Asia and Pacific Islands: the impact of climate change to 2030. Spec Rep NIC2009-006D. NIC, Washington, DC

Owosina A (1992) Methods for assessing the space and time variability of ground water data. MSc thesis, Utah State University, Logan

Paeth H, Scholten A, Friederichs P, Hense A (2008) Uncertainties in climate change prediction: El Niño-Southern Oscillation and monsoons. Global Planet Change 60: 265-288

Podestá G, Bert F, Rajagopalan B, Apipattanavis S and others (2009) Decadal climate variability in the Argentine Pampas: regional impacts of plausible climate scenarios on agricultural systems. Clim Res 40:199-210

Prairie J, Rajagopalan B, Fulp T, Zagona E (2006) Modified $\mathrm{k}-\mathrm{nn}$ model for stochastic streamflow simulation. J Hydrol Eng 11:371-378

Rajagopalan B, Lall U (1999) A k-nearest-neighbor simulation for daily precipitation and other weather variables. Water Resour Res 35:3089-3101

Schöngart J, Junk WJ (2007) Forecasting the flood-pulse in Central Amazonia by ENSO-indices. J Hydrol (Amst) 335:124-132

Sharif M, Burn DH (2007) Improved k-nearest neighbor weather generating model. J Hydrol Eng 12:42-51

> Singhrattna N, Rajagopalan B, Clark M, Kumar KK (2005a) Forecasting Thailand summer monsoon rainfall. Int $\mathrm{J}$ Climatol 25:649-664

Singhrattna N, Rajagopalan B, Kumar KK, Clark M (2005b) Interannual and interdecadal variability of Thailand summer monsoon season. J Clim 18:1697-1708

Singhrattna N, Babel MS, Perret SR (in press) Hydroclimate variability and long leading prediction of Thailand rainfall by large-scale atmospheric variables. Hydrolog Sci J

Tao F, Yokozawa M, Hayashi Y, Lin E (2003) Terrestrial water cycle and the impact of climate change. Ambio 32: 295-301

TMD (Thailand Meteorological Department) (2010) Climate statistics: climate charts. Available at: www.tmd.go.th/ en/climate.php?FileID $=7$

Trenberth KE (2008) The impact of climate change and variability on heavy precipitation, floods, and droughts. In: Anderson MG (ed) Encyclopedia of hydrological sciences. John Wiley \& Sons, Chichester, p 1-11

UNEP (United Nations Environment Programme) (2003) How will global warming affect my world? UNEP, Geneva 